\title{
Interference coatings based on synthesized silicon nitride
}

\author{
Cheng-Chung Lee, Hsuen-Li Chen, Jin-Cherng Hsu, and Chuen-Lin Tien
}

\begin{abstract}
Silicon nitrides are synthesized by ion-assisted deposition with only one coating material and a nitrogenion-beam source. All the $\mathrm{SiN}_{x}$ films are amorphous and mechanically strong. A wide range of refractive indices from 3.43 to 1.72 at a wavelength of $1550 \mathrm{~nm}$ is obtained. Near-IR antireflection coating and a bandpass filter based on the multilayers of $\mathrm{SiN}_{x}$ and $\mathrm{Si}$ are demonstrated. (C) 1999 Optical Society of America

OCIS codes: $310.0310,310.1620,310.1860,310.6860$
\end{abstract}

\section{Introduction}

$\mathrm{SiN}_{x}$ films are chemically stable and have good mechanical and optical properties. They have been synthesized by various methods and investigated by several authors. ${ }^{1-9}$ Among those methods, either a plasma-enhanced technique or chemical vapor deposition or a combination of these techniques has been studied. Most of those studies focused on the deposition technique and the analysis of film properties. However, simplifying the deposition process and reducing the absorption loss in making optical interference coatings still remain a challenge, especially for multilayer coatings in the near-IR region.

In this paper we report the systematical studies of the synthesis of $\mathrm{SiN}_{x}$ films by electron-beam evaporation of pure $\mathrm{Si}$ accompanied by $\mathrm{N}$-ion bombardment. This simplifies the coating process since only one coating material is needed. The results of the investigation on the composition, microhardness, and optical properties are described in detail. The optimum condition for depositing low-extinctioncoefficient films is explored. The application of the fabrication of a near-IR interference coating is demonstrated.

\section{Experiments}

Deposition is carried out on a cryopumped chamber with a basic pressure of $7 \times 10^{-7}$ Torr. Si with 99.99\% purity is the only material used as the start-

The authors are with the Institute of Optical Sciences, National Central University, Chung-Li (320), Taiwan. C.-C. Lee's e-mail address is cclee@ios704.ios.ncu.edu.tw.

Received 10 August 1998; revised manuscript received 17 December 1998.

0003-6935/99/102078-05\$15.00/0

(C) 1999 Optical Society of America ing material, and it is evaporated by an electronbeam gun. BK-7 glass and a Si wafer are used as substrates. The deposition rate $r$ is $\sim 0.07 \mathrm{~nm} / \mathrm{s}$, as measured by a quartz-crystal thickness monitor. Ion-assisted deposition is applied during the deposition. $\mathrm{N}_{2}$ is the only gas fed into the ion source as a working gas. No other gas or $\mathrm{N}_{2}$ is fed into the coating chamber during the synthesis of $\mathrm{SiN}_{x}$. Figure 1 is the schematic diagram of the deposition system. The ion source is a Kaufman type made by Ion Tech Inc. Ion-beam voltage $V_{b}$ and ion-beam current density $J$ are the only two adjustable parameters for synthesizing various $\operatorname{SiN}_{x}$. $J$ is measured by a Faraday cup that is set beneath the substrate before each deposition.

An x-ray diffractometer, x-ray photoelectron spectroscopy (XPS), and an IR spectophometer are used to investigate the structure and the stoichiometry of the deposited films. A microhardness tester is used to measure the relative hardness of the coatings, which is expressed in Vickers hardness (HV).

A Hitachi Model U-3501 spectrophotometer is used to measure spectra of the synthesized films. From the spectra, the refractive indices and the extinction coefficients are calculated by the envelope method. ${ }^{10}$

\section{Results and Discussions}

All the $\mathrm{SiN}_{x}$ films are amorphous, as measured by the $\mathrm{x}$-ray diffractometer.

The composition of $\mathrm{SiN}_{x}$ films can be found from XPS. For $J=0 \mu \mathrm{A} / \mathrm{cm}^{2}$ and $J=40 \mu \mathrm{A} / \mathrm{cm}^{2}$, the XPS spectra show only one peak at $-99.43 \mathrm{eV}$ (Fig. 2) and $-102.02 \mathrm{eV}$ (Fig. 3), respectively, which correspond to $\mathrm{Si}$ and $\mathrm{Si}_{3} \mathrm{~N}_{4}$, respectively. Figure 4 is the XPS spectrum of a $\operatorname{SiN}_{x}$ film deposited with $J=30$ $\mu \mathrm{A} / \mathrm{cm}^{2}$. The two peaks in Fig. 4 indicate that the film could be a mixture of $\mathrm{SiN}_{x}$ with a different ratio of $\mathrm{Si}_{3} \mathrm{~N}_{4}$ and $\mathrm{Si}$. 


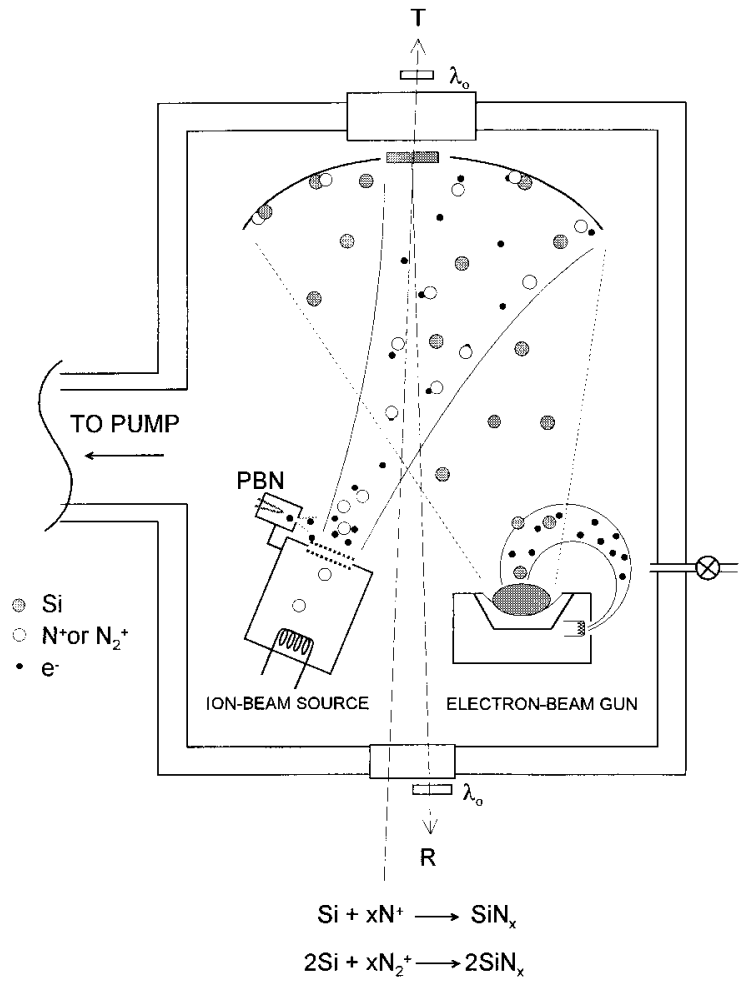

Fig. 1. Schematic diagram of the synthesis of $\operatorname{SiN}_{x}$ by IAD. PBN, plasma beam neutralizer.

No hydrogen was found, as some of the films were synthesized by chemical vapor deposition. This is also verified by examination of the absorption band in the IR spectrum. There is an absorption band only around $900 \mathrm{~cm}^{-1}$ that corresponds to the $\mathrm{Si}-\mathrm{N}$ bond.

The synthesized $\operatorname{SiN}_{x}$ films are very hard. Table 1 shows the microhardness of the films deposited on a Si wafer and BK-7 glass. The physical thickness of the films is $\sim 300 \mathrm{~nm}$. For comparison, the microhardnesses of the Si wafer and BK-7 glass are listed in Table 1: 1070 and $652 \mathrm{HV}$, respectively. The microhardness of the Si film increases from 684 and $435 \mathrm{HV}$ up to 965 and $634 \mathrm{HV}$ on the Si wafer and BK-7 glass, respectively, if the deposition is assisted by Ar-ion bombardment. All the synthesis films and



Fig. 2. XPS spectrum of a Si film; $J=0$.

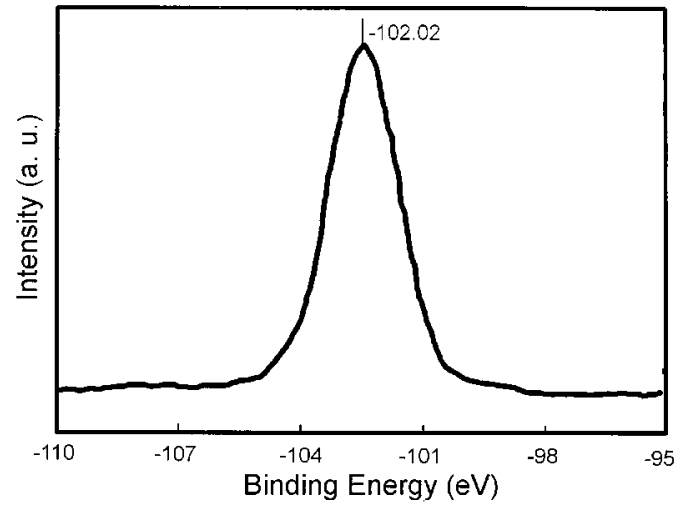

Fig. 3. XPS spectrum of $\mathrm{Si}_{3} \mathrm{~N}_{4}$ film, $J=40 \mu \mathrm{A} / \mathrm{cm}^{2}$.

the Ar-ion-assisted-deposited pure $\mathrm{Si}$ film were abraded 20 strokes with cheesecloth and no scratches were seen with a $150 \times$ microscope.

The spectra of single-layer $\mathrm{SiN}_{x}$ film deposited on BK-7 glass at various $J$ and $V_{b}=550 \mathrm{~V}$ are shown in Fig. 5. The refractive index $n$ and the extinction coefficient $k$ versus $J$ at a wavelength of $1550 \mathrm{~nm}$, as calculated by the envelope method, ${ }^{10}$ are shown in Fig. 6. Indices range from 1.72 to 3.43 , depending on the value of $J$. A graded refractive-index profile is useful for fabricating rugate filters. ${ }^{11,12}$ The var-

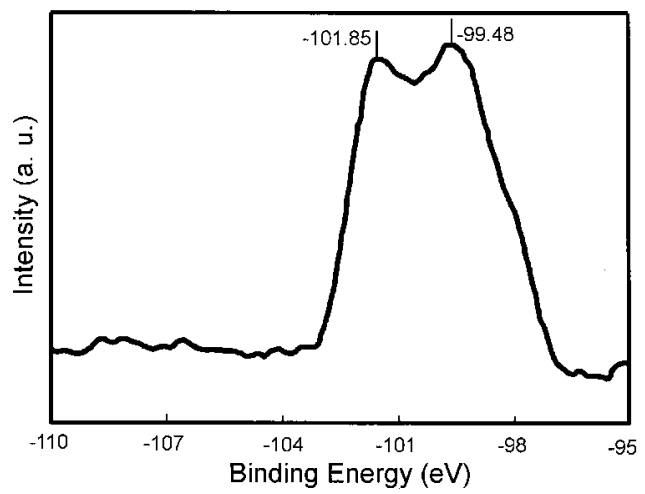

Fig. 4. XPS spectrum of a $\operatorname{SiN}_{x}$ film; $J=30 \mu \mathrm{A} / \mathrm{cm}^{2}$.

Table 1. Microhardness of Synthesized $\mathrm{SiN}_{x}$ and $\mathrm{Si}$ Films as a Function of Ion-Beam Current at lon-Beam Voltage $550 \mathrm{~V}$

\begin{tabular}{ccc}
\hline $\begin{array}{c}\text { Nitrogen-ion current density } \\
\left(\mu \mathrm{A} / \mathrm{cm}^{2}\right)\end{array}$ & $\begin{array}{c}\text { Substrate } \\
(\text { Si Wafer }) \\
(\mathrm{HV})\end{array}$ & $\begin{array}{c}\text { Substrate } \\
(\mathrm{BK}-7 \text { Glass }) \\
(\mathrm{HV})\end{array}$ \\
\hline 40 & 1256 & 747 \\
30 & 1246 & 738 \\
20 & 1148 & 707 \\
10 & 1121 & 692 \\
0 & 684 & 435 \\
0 & 965 & 634 \\
$($ But IAD with & & \\
Ar-ion beam & & \\
$\left.40 \mu \mathrm{A} / \mathrm{cm}^{2}\right)$ & & \\
Hardness of Si wafer $=1070 \mathrm{HV}$ & & \\
Hardness of BK-7 glass $=652 \mathrm{HV}$ & & \\
\hline
\end{tabular}




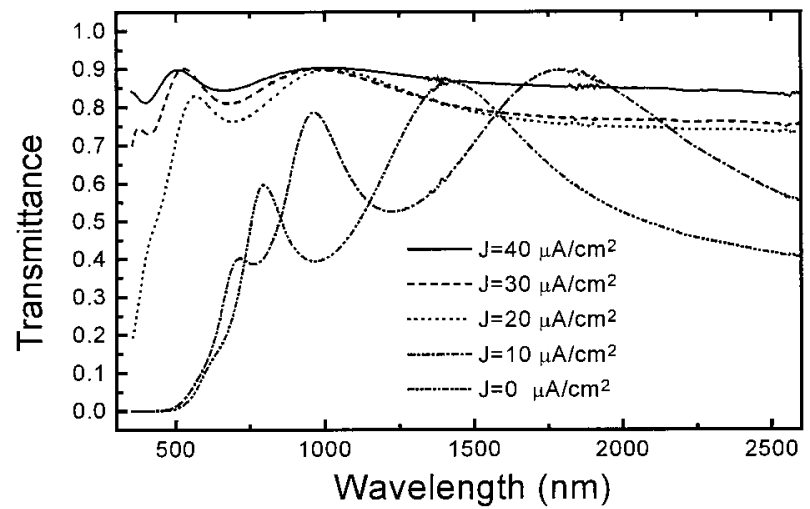

Fig. 5. Spectra of $\mathrm{SiN}_{x}$ films deposited on BK-7 glass with various ion-beam current densities $(J)$.

ious indices also benefit the fabrication of other types of optical interference coatings, as shown below.

Both $n$ and $k$ are $V_{b}$ dependent and are optimal at $550 \mathrm{~V}$. We have tried $V_{b}$ from 0 to $700 \mathrm{~V}$ and find that the value of $k$ increases when $V_{b}$ is greater than or less than $550 \mathrm{~V}$. For $V_{b}$ greater than $550 \mathrm{~V}$ the nitrogen gases could penetrate into the film and be trapped inside the film. On the other hand, if $V_{b}$ is less than $550 \mathrm{~V}$, the film would not be so dense. In both cases, the film could have larger $k$ or lower $n$. Such a result is consistent with the results of Ref. 13 . Therefore we fixed $V_{b}=550 \mathrm{~V}$ and adjusted the $J$ value to get the desired refractive indices to fabricate multilayer interference filters. Under this condition and with $J=40 \mu \mathrm{A} / \mathrm{cm}^{2}$, we have a $\mathrm{Si}_{3} \mathrm{~N}_{4}$ film with $n=1.72$ and $k$ less than $10^{-5}$ at a wavelength of 1550 $\mathrm{nm}$ within the experimental uncertainty of the measured transmittance.

If we assume that the synthesized $\mathrm{SiN}_{x}$ is a film composed of $\mathrm{Si}$ and $\mathrm{Si}_{3} \mathrm{~N}_{4}$, then the effective refractive index of the films can be derived. Let $n_{A}$ and $n_{B}$ be the refractive indices of two composite materials and $q$ be the volume fraction of material A; then the effective refractive index of the composite film $n$, by the Bruggeman expression, ${ }^{14,15}$ is

$$
q \frac{n_{A}^{2}-n^{2}}{n_{A}^{2}+2 n^{2}}+(1-q) \frac{n_{B}^{2}-n^{2}}{n_{B}^{2}+2 n^{2}}=0 .
$$



Fig. 6. Refractive index and extinction coefficient of $\operatorname{SiN}_{x}$ films at $1550 \mathrm{~nm}$.

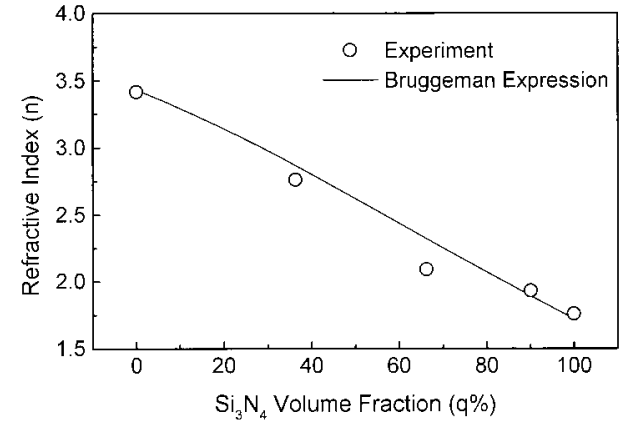

Fig. 7. Refractive index of synthesized $\mathrm{SiN}_{x}$ films versus $\mathrm{Si}_{3} \mathrm{~N}_{4}$ volume fraction $(q \%)$.

Let $\mathrm{Si}_{3} \mathrm{~N}_{4}$ be material A; the refractive indices of the synthesized film are dependent on the fraction $q$, as shown in Fig. 7 (solid curve). The experimental data are quite close to the Bruggeman expression with small deviations at $q=0.36$ and $q=0.66$, which correspond to $J=10 \mu \mathrm{A} / \mathrm{cm}^{2}$ and $J=20 \mu \mathrm{A} / \mathrm{cm}^{2}$, respectively. This deviation might be due to the error in calculating the refractive index since the film is not very thick. The thickness of the film is $\sim 300$ $\mathrm{nm}$; the peaks and valleys are therefore not very clear in the spectrum around the near-IR. This is the disadvantage of using the envelope method to calculate the refractive index if the film thickness is too thin. In any case, the curve shows that the index of the synthesized film depends on the value of $q$ with $n=3.43$ when $q=0$ and $n=1.72$ when $q=1$ at a wavelength of $1550 \mathrm{~nm}$.

From the deposition rates $r$ and the ion-beam current density $J$ we also find that $q$ is a function of $J$ and ion/atom ratio $\alpha$. The relations between $J$ versus $q$ and $\alpha$ versus $q$ are shown in Fig. 8 according to experimental data and the following equation:

$$
\alpha=(J / Q) /(\rho r),
$$

where $Q=1.6 \times 10^{-19} \mathrm{C}$ is the electron charge and $\rho=4.9 \times 10^{22}$ atoms $/ \mathrm{cm}^{3}$ is the atomic density for an amorphous $\mathrm{Si}{ }^{16}$

When $J=40 \mu \mathrm{A} / \mathrm{cm}^{2}$ and $q=1$, that means Si was fully nitrified. The $\mathrm{N}$ ion to $\mathrm{Si}$ atom ratio is 0.73 at that condition.

The wide range of various refractive indices of $\mathrm{SiN}_{x}$ is very useful for optical coatings. Figure 9 is an example of an antireflection (AR) coating on one side of a ground $\mathrm{Si}$ wafer. It is a single-layer quarterwave $\operatorname{SiN}_{x}$ with $n=1.85$.

Figure 10 is a short-wavelength-pass filter deposited on a Si wafer: $\mathrm{ARC} / \mathrm{Si}$-sub/M(HL $)^{3} \mathrm{H} 0.5 \mathrm{~L} /$ Air, where $\mathrm{M}, \mathrm{H}$, and $\mathrm{L}$ are quarter-wave optical thickness of $\operatorname{SiN}_{x}$ with indices $2.4,3.4$, and 1.72, respectively; $M$ is a match layer to increase the transmittance in the pass range; and ARC is an AR coating on the backside of the silicon wafer (Si-sub). The short-wavelength cut is due to the intrinsic absorption of Si. The final optical performance of the coatings is then a bandpass filter.

The above demonstration was done in a small 

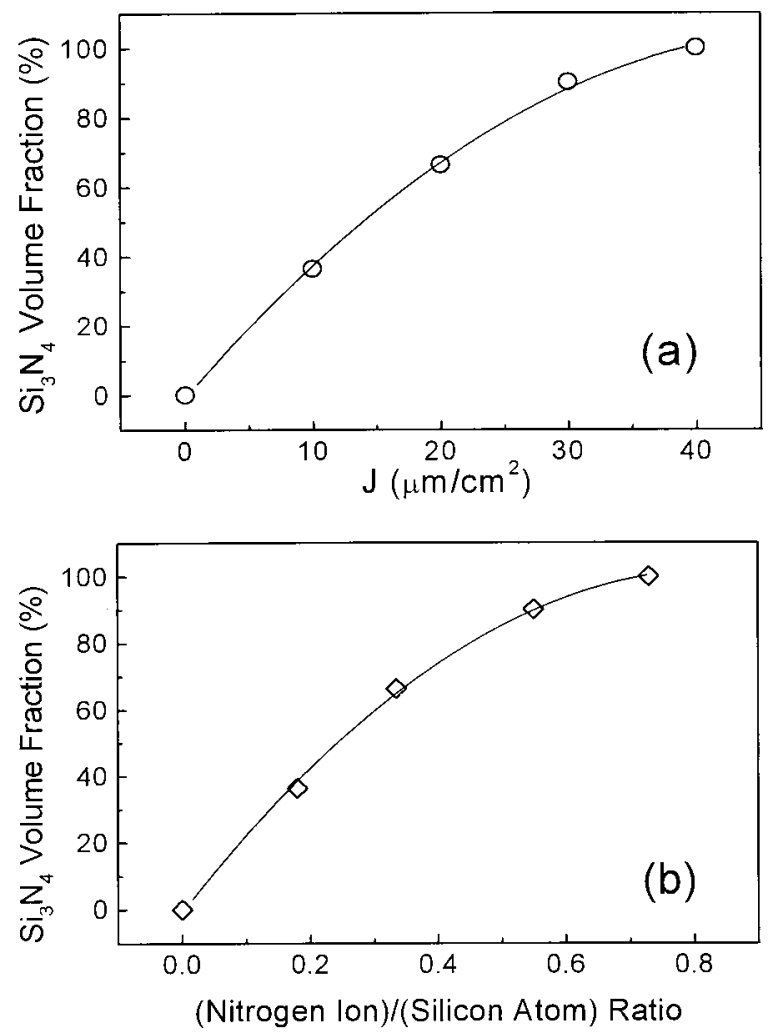

Fig. 8. Volume fraction $(q \%)$ of $\mathrm{Si}_{3} \mathrm{~N}_{4}$ versus (a) ion current density, (b) ( $\mathrm{N}$ ion $) /(\mathrm{Si}$ atom) ratio.

coater. With a large crucible we then could have enough material to manufacture block filters and bandpass filters for a wavelength division multiplex$\mathrm{er}^{17}$ with only one coating material, $\mathrm{Si}$, and using less layers than conventional methods. It could simplify the coating process a lot. However, reducing the $k$ value for $\operatorname{SiN}_{x}$, where $x$ is less than 1.33, is necessary if a low-loss coating is required. It needs more work, such as adjusting the coating parameters and the substrate temperature and using a second ion source.

In conclusion, we have demonstrated the advantage of using an ion source in the coating process, the technique of synthesized silicon nitrides and the coating of thin-film filters, by using only one coating ma-

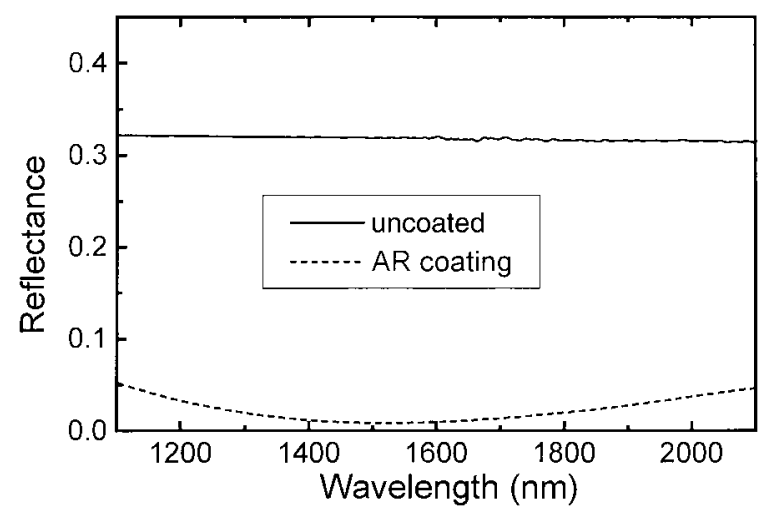

Fig. 9. Single-layer AR coating on one side of a ground $\mathrm{Si}$ wafer.

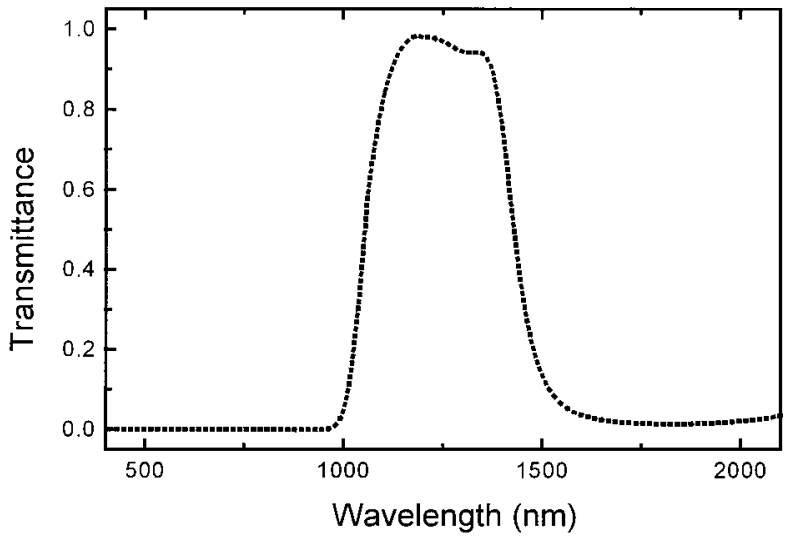

Fig. 10. Short-wavelength-pass filter deposited on a Si wafer with an AR coating on the backside.

terial. The film is mechanically strong. The coating process is much simpler and more reproducible than conventional methods.

We acknowledge the sponsors of the National Science Council under contract NSC86-2215-E-008-008, Taiwan, Industrial Technology Research Institute, Hsinchu, Taiwan, and DiCon Fiberoptics, Inc., Berkeley, Calif.

\section{References}

1. B. G. Bovard, J. Ramm, R. Hora, and F. Hanselmann, "Silicon nitride thin films by low voltage reactive ion plating: optical properties and composition," Appl. Opt. 28, 4426-4421 (1980).

2. R. Y. Tsai, L. C. Kuo, and F. C. Ho, "Amorphous silicon and amorphous silicon nitride films prepared by plasma-enhanced chemical vapor deposition process as optical coating materials," Appl. Opt. 32, 5561-5566 (1993).

3. P. Boher, P. Houdy, L. Hennet, and D. J. Smith, "Silicon/ silicon oxide and silicon/silicon nitride multilayers for extreme ultraviolet optical applications," Opt. Eng. 30, 1049-1061 (1991).

4. Y. Cros and J. C. Rostaing, "Optical properties of plasmaenhanced chemical vapor deposition silicon oxynitride films," J. Appl. Phys. 62, 4536-4544 (1987).

5. P. V. Bulkin, P. L. Swart, and B. M. Lacquet, "Optical properties of $\mathrm{SiN}_{x}$ deposition by electron cyclotron resonance plasma enhanced deposition," Opt. Eng. 33, 2894-2897 (1994).

6. P. V. Bulkin, P. L. Swart, and B. M. Lacquet, "Electron cyclotron resonance plasma deposition of $\mathrm{SiN}_{x}$ for optical applications," Thin Solid Films 241, 247-250 (1994).

7. T. Inukai and K. Ono, "Optical characteristics of amorphous silicon nitride thin films prepared by electron cyclotron resonance plasma chemical vapor deposition,” Jpn. J. Appl. Phys. 33, 2593-2598 (1994).

8. R. P. Netterfield, R. J. Martin, and W. G. Sainty, "Synthesis of silicon nitride and silicon oxide films by ion-assisted deposition," Appl. Opt. 25, 3808-3809 (1986).

9. E. Dehan, P. Temple-Boyer, R. Henda, J. J. Pedroviejo, and E. Scheid, "Optical and structural properties of $\mathrm{SiO}_{x}$ and $\mathrm{SiN}_{x}$ materials," Thin Solid Films 266, 14-19 (1994).

10. R. Swanepoel, "Determination of the thickness and optical constants of amorphous silicon," J. Phys. E 16, 1214-1222 (1983).

11. E. P. Donovan, D. V. Vechten, A. D. F. Kahn, C. A. Carosella, and G. K. Hubler, "Near infrared rugate filter fabrication by 
ion beam assisted deposition of $\mathrm{Si}_{(1-x)} \mathrm{N}_{x}$ films," Appl. Opt. 28, 2940-2944 (1989).

12. P. L. Swart, P. V. Bulkin, and B. M. Lacquet, "Rugate filter manufacturing by electron cyclotron resonance plasmaenhanced chemical vapor deposition of $\mathrm{SiN}_{x}$," Opt. Eng. 36, 1214-1219 (1997).

13. C. C. Lee, Y. Y. Liou, and C. C. Jaing, "Improvement of the homogeneity of optical thin films by ion-assisted deposition," J. Mod. Opt. 43, 1149-1154 (1996).

14. L. Ward, "Effective medium theory," in The Optical Constants of Bulk Materials and Films (Institute of Physics, Bristol, 1992), Section 8.3, p. 246.
15. Y. M. Xiong, P. G. Snyder, and J. A. Woollam, "Controlled index of refraction silicon oxynitride films characterized by variable angle spectroscopic ellipsometry," Thin Solid Films 206, 248-253 (1991).

16. G. K. Hubler, "Fundamentals of ion-beam-assisted deposition: Technique and film properties," Mater. Sci. Eng. A 115, 181192 (1989).

17. D. Cushing, "Bandpass filters for communications," in Optical Interference Coatings, Vol. 17 of 1995 OSA Technical Digest Series (Optical Society of America, Washington, D.C., 1995), FA4-1/429-430. 